\title{
RECONSTITUIÇÃO DO GEOSSINCLINAL MINAS ATRAVÉS DE SUAS ISÓPACAS - INTERESSE METALOGENÉTICO
}

\author{
LUIZ CARLOS MIGUEL DE SÁ*
}

\begin{abstract}
This work was based on the construction of isopacs taken from a group of rocks pertaining to a miogeosyncline (miogeosyncline Minas of the Quadrilatero Ferrifero). The majority of the data used for the construction of the isopacs was obtained through published works of the joint commission of the USGS/DNPM.

The study of the distribution of these isopacs gives one the ability to visualize the characteristics and line of transport of this series, i.e., North-South/East-West. Therefore the study of this miogeosyncline permits one to make some conjecture as to the development of the "Minas geosyncline" and the metallogenic interest related to it.
\end{abstract}

INTRODUÇÃo Baseado nos dados fornecidos pelos relatórios USGS/DNPM de 1968 a 1969 para o Quadrilátero Ferrífero, tentou-se elaborar algumas cartas de isópacas da série Minas.

O interesse apresentado por esse tipo de carta é de permitir a visualização dos grandes traços topográficos de uma bacia, os quais não deixam de influenciar as grandes direções de transporte e de fácies sedimentares da mesma (Asquith, 1970; Krumbrein e Sloss, 1963).

Para análise do desenvolvimento de um geossinclinal, o autor se baseou em conceitos citados e estabelecidos por autores como Auboin (1965), Bird e Dewey (1970), Contescu (1974), Dietz (1963), Kay (1951), Krumbrein e Sloss (1963), Pettijohn, Potter e Siever (1972).

Segundo Dietz (1963, 1972), poder-se-ia identificar a existência atual de pares geossinclinais (miogeossinclinal-eugeossinclinal) representados pelos sedimentos típicos como os da costa atlântica, onde a plataforma continental abriga sedimentos miogeossinclinais e a zona batial e abissal abrigariam sedimentos eugeossinclinais. Os sedimentos carbonatados de uma plataforma são os mesmos representados por uma plataforma estável, e são típicos de sedimentos miogeossinclinais (Dietz, 1963; Dewey e Bird, 1970).

De acordo com Pettijohn, Potter e Siever (1972), a seqüência sedimentar observada numa fase de geossinclinal é a apresentada no organograma da Tab. 1, onde se tem sempre uma série de ortoquartzitos na base de miogeossinclinais representando o estágio gerador, seguida de uma fase pelitica e esta por uma carbonatada, todo o grupo representando o estágio gerador e o de desenvolvimento.

O estágio flysch (pré-orogênico) seria registrado por uma sedimentação de grauvacas, tendo-se desenvolvido as direções preferenciais de transporte dos sedimentos no sentido oposto à do estágio gerador. Aparece também o registro de restos de sedimentos das séries sotopostas, fato este chamado de fase de canibalismo por Pettijohn (1975).

Segundo Mattehews (1974), os sedimentos flyschs e molassas são também termos tectônicos; os flyschs são interpretados como sedimentos pré-orogênicos e orogênicos, e neste caso dobrados conjuntamente com os sedimentos sotopostos, ou seja, aqueles da fase do estágio de desenvolvimento e os pré-flyschs.

Segundo Mattehews (1974), que utiliza a classificação de Kay (1951), os flyschs seriam depositados num ambiente exogeossinclinal, que nada mais seria que a deposição de uma seqüência de rochas de composição de grauvacas depositadas sobre um miogeossinclinal e originados de uma seqüência de sedimentos que foram depositados no ambiente de eugeossinclinal em estado de levantamento e dobramento.

Seria no estágio orogênico terminal ou orogênico tardio que apareceria a deposição de uma seqüência de subgrauvacas e protoquartzitos chamada de molassa, e que seria discordante daquelas depositadas precedentemente, inclusive dos flyschs, tendo à sua base uma seqüência de um vulcanismo andesítico, podendo ir até aos termos riolíticos, com intrusões graniticas e granodioriticas (vulcanismo calco-alcalino), na parte eugeossinclinal.

Todos esses fatores, quando analisados conjuntamente, permitem, então, fazer algumas importantes conjecturas sobre a "bacia minas" em si mesma, como também nos servirá de direção em possíveis trabalhos futuros. Enfim essa análise levará forçosamente a uma melhor adequação de nossos conhecimentos sobre este grupo de rochas denominado "minas".

ANÁLISE ESTRATIGRÁFICA DAS SEQÜÊNCIAS LITOLÓGICAS DA SÉRIE MINAS A estratigrafia aqui adotada para a série Minas é a mesma que foi proposta pelo convênio USGS/DNPM, a fim de não se confundir terminologias, haja visto o registro dos trabalhos até então elaborados nesta área. O autor toma como dado de base o trabalho acima referido, sendo então a estratigrafia adotada a que pode ser vista na Tab. 2 .

$\mathrm{O}$ importante dessa divisão estratigráfica para o quadrilátero (Door II et al., 1969) é a utilização da classificação petrográfica e geométrica dos corpos sedimentares areníticos, agora quartzitos. Esta classificação simplificada sob o ponto de vista sedimentológico também

* Rua Guilherme Peret, 25 - CEP 35400 - Ouro Preto (MG). 


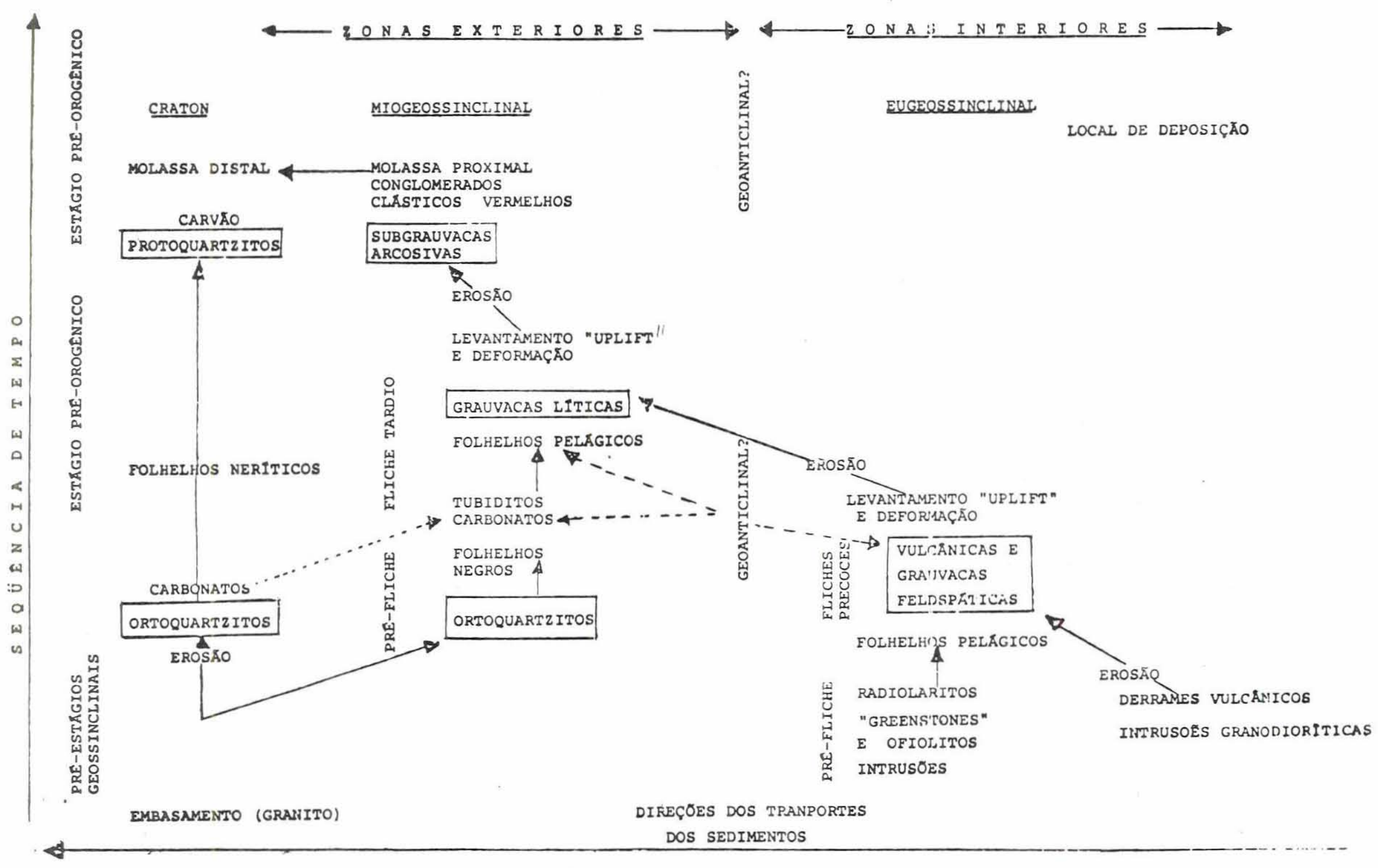


Tabela 2 - Sumário estratigráfico do Quadrilátero Ferrífero (segundo Door, J.V.N. - USGS - PP641-A)

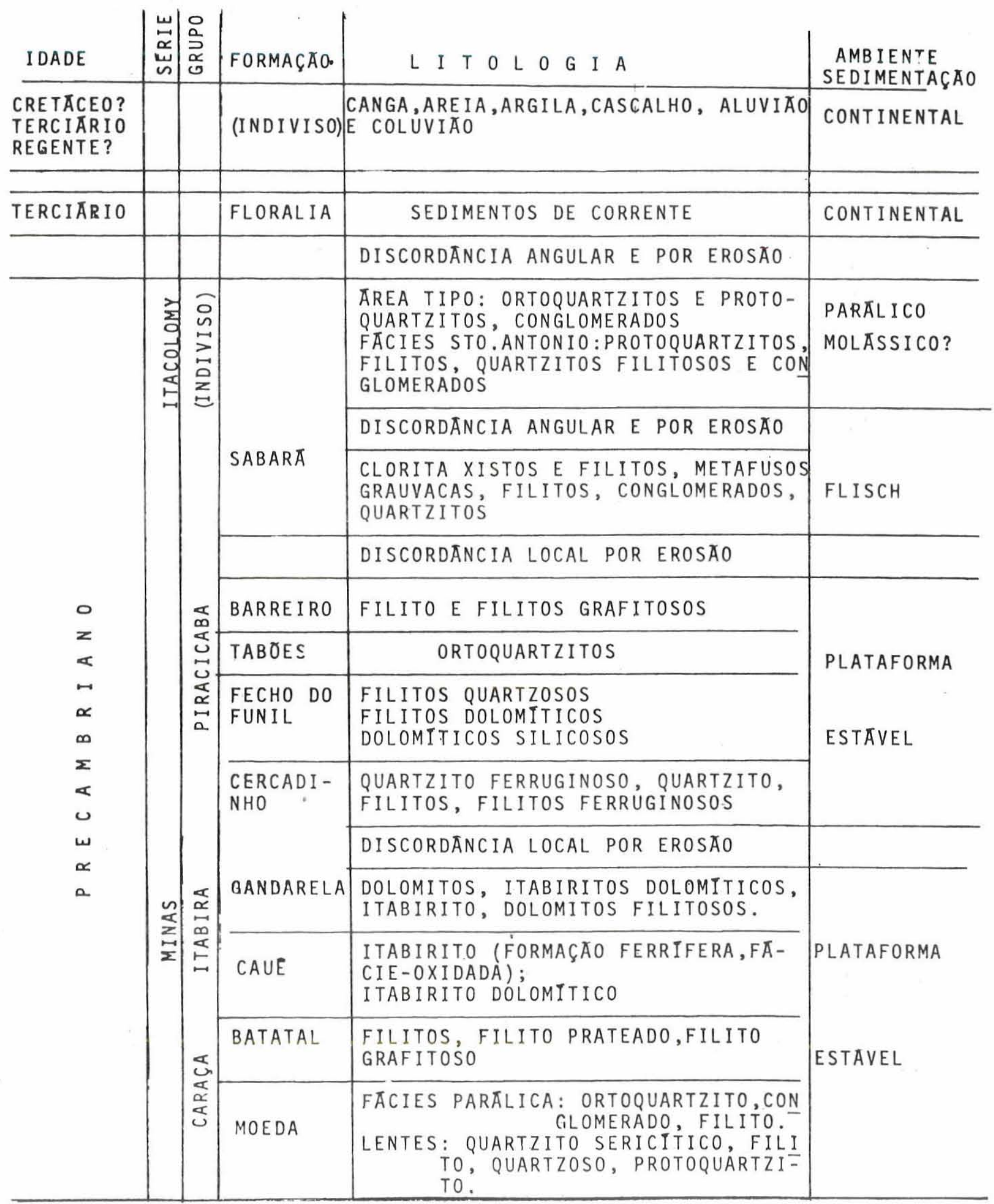


foi adotada por Pettijohn (1957), Pettijohn, Potter e Siever (1972), Krumbrein e Sloss (1963), e se torna muito importante sob o aspecto interpretativo, consistentemente com o modelo geossinclinal.

Grupo Caraça/Grupo Itabira Uma análise vertical da deposição das formações Moeda, Batatal, Cauê e Gandarela nos permite a visualização de uma seqüência litológica, cuja granulometria mais grosseira (Moeda) passa para sedimentos pelíticos (Batatal) e para os colóides pelíticos, chegando até precipitação química (Cauê, Gandarela), onde encontramos calcários e dolomitos.

Uma comparação dessa seqüência com a seqüência lombardiana (Lombard, 1956, 1972), permite visualizar um alto grau de concordância entre a disposição vertical dos sedimentos encontrados nos grupos Caraça/Itabira da série Minas com a disposição típica da série lombardiana positiva, ou seja, uma seqüência transgressiva de plataforma. É interessante, dentro desse caso, notar a ordem de grandeza da espessura da seqüência lombardiana, que é de centena de metros, com seqüência fluvial ou a sequiência da Bersier (Bersier, 1958), que tem uma disposição vertical do pacote sedimentar parecida com a de Lombard, mas numa ordem de grandeza de dezenas de metros.

Segundo Delfoud (1974), a seqüência lombardiana corresponde a uma seqüência do tipo arenito, margas e calcários, e traduz uma diminuição do material de origem continental. Esse tipo de seqüência é encontrado sobre as plataformas alimentadas por materiais que provêm de fontes distantes e que se misturam dentro de uma sedimentação recifal. Na maioria das vezes, estas seqüências são completadas por um termo suplementar de argilas tipicamente marinhas, que vêm do largo.

Esses termos (série de Lombard) são considerados de plataforma estável, segundo classificação já consagrada de Krumbrein e Sloss (1968).

Grupo Piracicaba O Grupo Piracicaba, segundo Door II (1969), foi dividido em quatro formações, se se considera a Formação Sabará à parte. Esses sedimentos foram classificados como de plataforma estável (cobertura por Door II, acima citado) devido à presença de ortoquartzitos nas formações Cercadinho e Taboões.

A presença constante dos laminitos II nos leva a pensar, de acordo com Wood e Smith (1959), também em laminações do fronte de um delta, produzidas pelas correntes de tração de fundo agindo conjuntamente com a gravidade sobre as partículas que tombam num plano inclinado, devido ao movimento da água. A gradação inversa dos estratos da formação F. Funil que termina num Taboões grosseiro, e que indica regressão, é bem sugestiva de um ambiente deltáico ou regressivo marinho para esses sedimentos.

Dardenne e Costa (1975) assinaram a presença de estromatólitos, possivelmente do tipo Baicalia, na Formação Cercadinho, o que permitiu datar estes sedimientos como do Rifeano (1.350-950 ma); uma análise mais detalhada das fácies das formações do Grupo Piracicaba será feita abaixo.

Cercadinho Na região próxima a Ouro Preto, pode ser encontrada dentro desta formação uma combinação de figuras sedimentares com as seguintes características: estratificações cruzadas de pequeno ângulo de inclinação em relação ao plano horizontal, "Scour and fill", bem como estratificações cruzadas de sensos opostos (herrigbone). Esses quartzitos são finamente laminados, apresentando uma seqüência de laminações típicas de regiões de marés, ou seja, alternações argilosas, e de níveis com estratificação cruzada de um arenito mais grosseiro intercalados a arenitos mais finos, e que apresentam laminações horizontais (Clifton, Hunter e Philips, 1971). Os fatos analisados acima nos permitem concluir que sedimentos da Formação Cercadinho, na região próxima a Ouro Preto, foram depositados numa região de marés pelos fatos seguintes:

1) rápidas mudanças no sentido das correntes de deposição,

2) alternância em pequena escala de fortes correntes com águas calmas,

3) alternâncias de erosão e de deposição.

Fecho do Funil A Formação do Fecho do Funil na região estudada é de mais ou menos 200 m de sedimentos compostos de filitos na base e de niveis mais quartzíticos no topo. Essa seqüência de sedimentos, gradando do pólo argila ao pólo arenito no topo, pode sugerir uma fase regressiva de tipo costa ou seqüência deltáica, caracterizada pela seqüência gradacial inversa segundo Vischer (1964), Mattehews (1974).

Taboões É muito parecido com a parte superior da Formação Cercadinho. Os ortoquartzitos ai também sugerem sedimentos depositados numa praia em virtude das laminações horizontais dos sedimentos, a maturidade do arenito e o baixo ângulo das estratificações cruzadas.

Barreiro É caracterizado por uma espessa série de filitos com intercalações de filitos grafitosos; estes níveis de filitos grafitosos sugerem uma região lagunar para a formação destes lutitos. Aí é também encontrado níveis conglomeráticos, onde no meio de uma matriz argilo-siltosa encontram-se seixos de 2 a $5 \mathrm{~cm}$ de diâmetro, podendo mesmo ser encontrados blocos de 20 a $30 \mathrm{~cm}$ de diâmetro de quartzitos. Esses blocos de quartzitos são facilmente correlacionáveis com os niveis quartzíticos das formações sotopostas, ou seja, da Formação Cercadinho ou da Formação Taboões. A presença de matações e seixos de formações sotopostas dentro do Barreiro sugere a existência de instabilidade da Bacia, já na época da deposição do Barreiro. Seria a fase canibalística sugerida por Pettijohn (1975), que começaria na época da deposição do Barreiro? Isso poderia nos levar a considerar essa formação como já pertencente à fase flysch?

ISÓPACAS DA SÉRIE MINAS As cartas isópacas foram construidas a partir de dados colhidos nos relatórios USGS/DNPM de 1963 em várias regiões do Quadrilátero Ferrífero, e com dados do autor, principalmente na região de Outro Preto, e seus resultados podem ser vistos sobre as Figs. 2, 3, 4 e 5.

Depois das análises das seqüências estratigráficas da série Minas, principalmente nos grupos Caraçá, Itabi- 
ra e Piracicaba, pode-se constatar que essas rochas se enquadram em uma seqüência típica de miogeossinclinal.

Dentro deste trabalho, para que a análise das isópacas seja coerente com os trabalhos de Dietz (1963), Bird e Dewey (1974), devemos considerar somente aquelas que formam uma seqüência de plataforma, excetuando-se, no caso, as isópacas do Grupo Sabará e possivelmente Barreiro, que seriam completamente fora do contexto aqui considerado, por serem rochas pertencentes a um flysch, rochas então sedimentadas num exogeossinclinal, segundo Mattehews (1974), Bird e Dewey (1970) e outros.

Segundo Dietz (1963 e 1974) as formações miogeossinclinais têm uma forma trapezoidal, com uma parte mais espessa, ou seja, a base do trapézio situada na parte mais externa da zona miogeossinclinal. Podemos também ver que, ao lado de um miogeossinclinal, temos o desenvolvimento de um eugeossinclinal formando pares e obedecendo mais ou menos a um desenvolvimento cíclico, como pode se ver pelo desenho da Fig. 1.

Como o Grupo Piracicaba não está completamente presente em todo o Quadrilátero Ferrífero (faltam as formações Fecho do Funil, Taboões e Barreiro na parte norte-nordeste do quadrilátero), e a presença do Grupo Tamanduá na região nordeste do quadrilátero, fornece-nos dois fatores que podem ser objeto de uma breve análise, sendo considerados como se segue:

1) Neste trabalho não se considerará a Grupo Tamanduá. Para tanto dois outros fatores devem ser levados em consideração no uso dos dados para que aqueles não influenciem nos resultados.

1.1) Resumida extensão da ocorrência do Grupo Tamanduá: ele ocorre somente ao nordeste do Quadrilátero Ferrífero, nas serras do Caraça e de Ouro Branco, em comparação com a grande extensão da Moeda. Possivelmente, os dois não possuẹm um mesmo modelo de formação.

1.2) Segundo Simmons e Maxwell (1961), o Grupo Tamanduá ocupa uma posição intermediária entre a série Rio das Velhas e a série Minas. Por causa desses dois fatos citados, consideraremos a construção das isópacas somente a partir da Formação Moeda.
2) Foi nosso intuito considerar toda a série Minas até a base da Formação Sabará, fato este que incluiria todas as formações pertencentes à plataforma Minas para a construção das isópacas e, conseqüentemente, em nada transformaria o modelo aqui considerado, em relação com aquele tratado por outros autores. No nosso caso, há ainda um pequeno problema que é o hiato ou a erosão atual (posterior ou geossinclinal) das formações estratigráficas, superior à Formação Cercadinho na região norte-nordeste do Quadrilátero Ferrífero. Neste caso, considerar-se-á somente até a Formação Cercadinho, e o modelo seria assim determinado: os grupos Caraça, Itabira e Piracicaba fazendo parte de uma plataforma estável, considerado como sedimentos pré-flyschs, e a Formação Sabará (e talvez o Barreiro) como sedimentos já tipo flysch, estes não mais pertencentes a uma plataforma estável.

Belo Horizonte/Serra do Curral A região de Belo Horizonte/Serra do Curral foi cartografada por Pomerene (1964). Nesta região, as espessuras variam muito devido ao dobramento sobre si mesma das formações, em muito aumentando as verdadeiras espessuras de várias localidades da quadricula, principalmente as da região de Belo Horizonte, Macacos e Ibirité.

Barreiro - 107 m; Taboões - de mais ou menos $300 \mathrm{~m}$, sendo que na localidade o tipo é $121 \mathrm{~m} ; F$. Funil - 150 $\mathrm{m}$ em vários lugares; varia de 25 a $550 \mathrm{~m}$. Em Belo Horizonte é aproximadamente $200 \mathrm{~m}$; Cercadinho - $80 \mathrm{~m}$ em Morro do Cercadinho e $317 \mathrm{~m}$ em Belo Horizonte; Gandarela - varia de $500 \mathrm{~m}$ de Macacos a $900 \mathrm{~m}$ em Belo Horizonte. Pomerene indica que a espessura verdadeira é de aproximadamente $400 \mathrm{~m}$ na região de Acaba Mundo; Cauê - varia de $950 \mathrm{~m}$ a $250 \mathrm{~m}$ na região de Macacos; na Serra da Jangada (Ibirité) é de mais ou menos $700 \mathrm{~m}$, sendo que varia de $100 \mathrm{~m}$ a SW de Belo Horizonte a $300 \mathrm{~m}$ em Águas Claras; Batatal — é de $500 \mathrm{~m}$ em Belo Horizonte, variando de $100 \mathrm{~m}$ a $500 \mathrm{~m}$ em Macacos e de $100 \mathrm{~m}$ a $200 \mathrm{~m}$ entre Belo Horizonte e Ibirité; Moeda - foi considerado subtraindo-se a espessura média do Grupo Caraça em relação à espessura média da Formação Batatal; Caraça - varia de $400 \mathrm{~m}$ a $800 \mathrm{~m}$ na região de Macacos, sendo de $100 \mathrm{~m}$ no Rochedo das

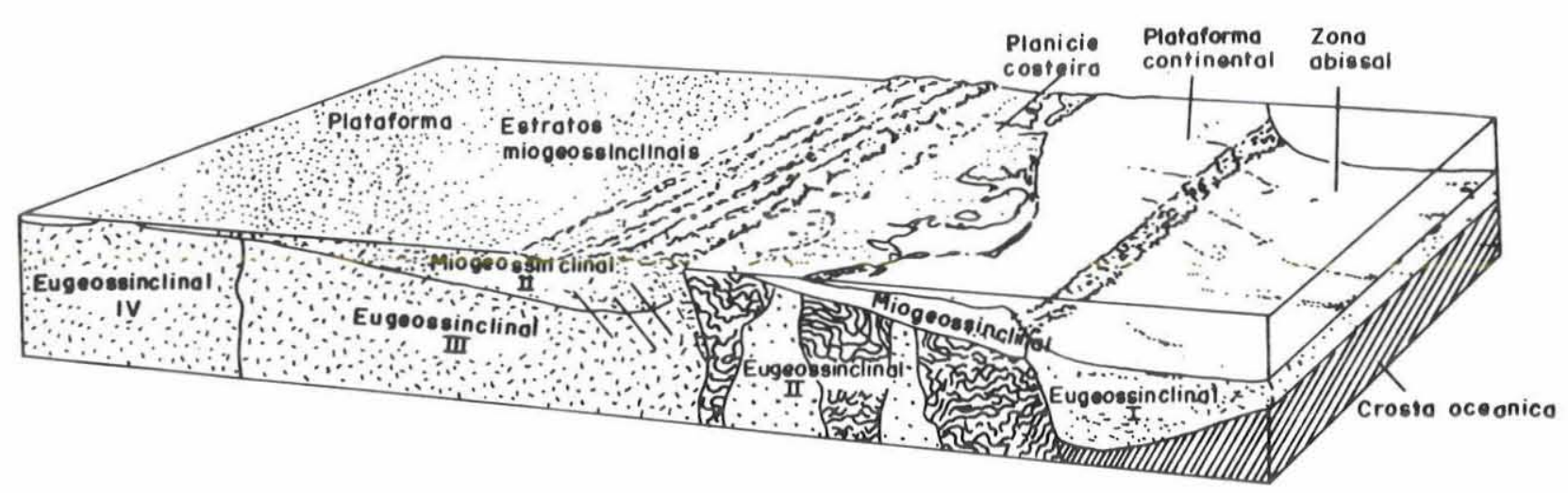

Figura 1 - Desenvolvimento de geossinclinais no tempo geológico segundo Dietz (1972) 


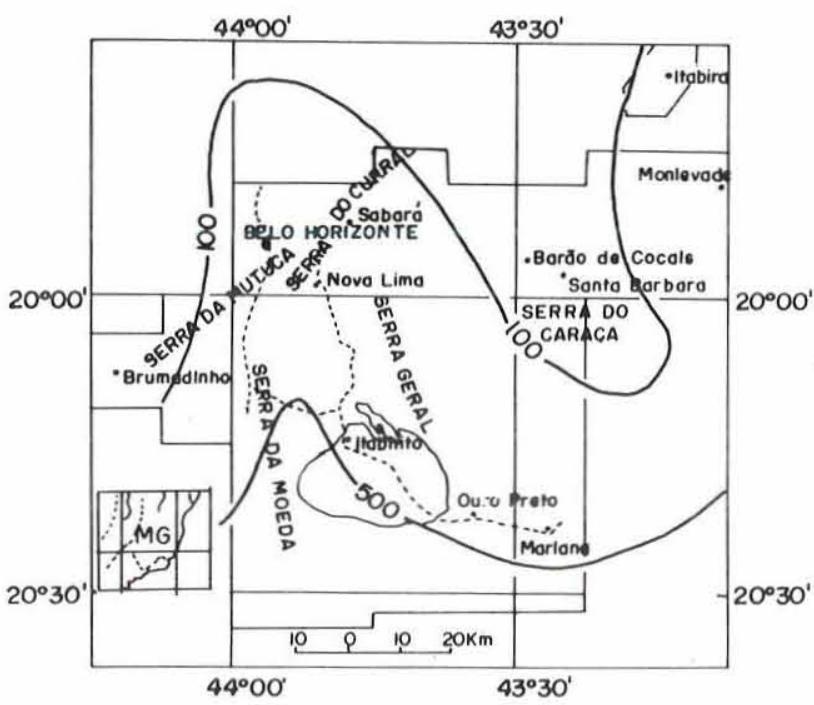

Figura 2 - Carta isópaca da Formação Moeda

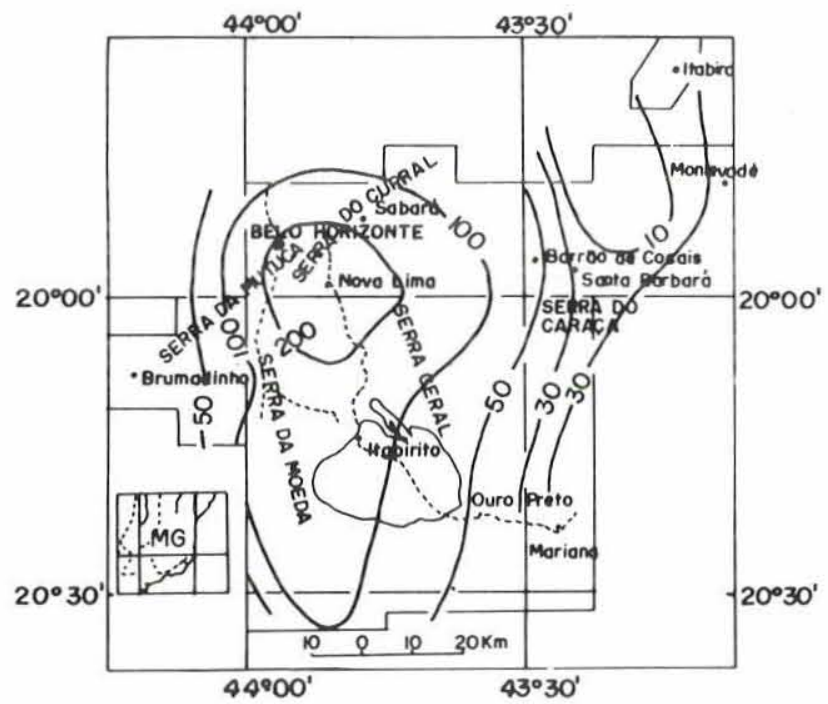

Figura 3 - Carta isópaca da Formação Batatal

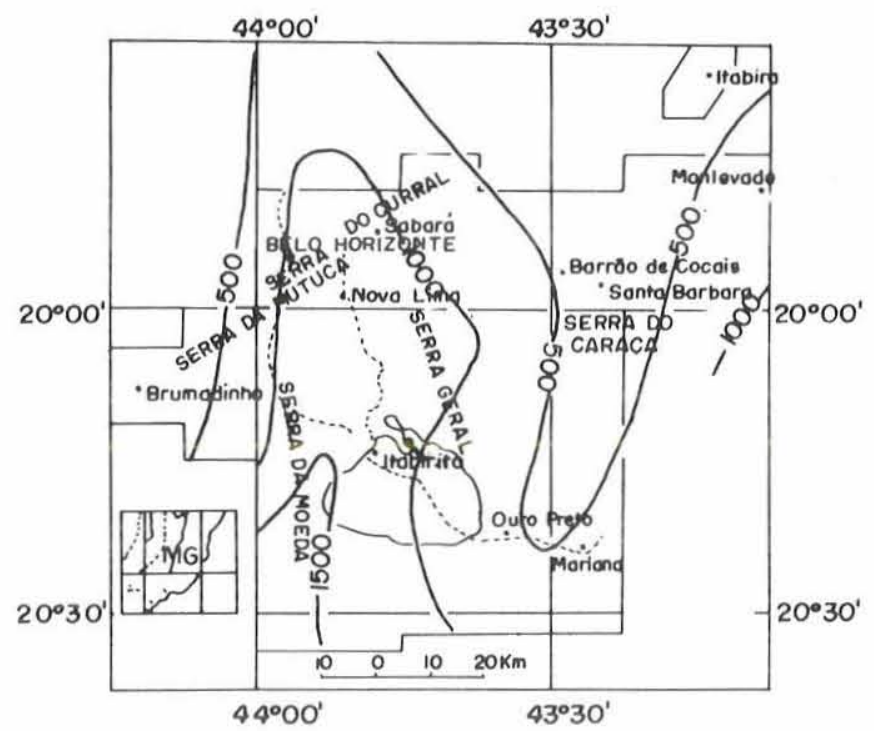

Figura 4 - Cartas isópacas dos grupos Caraça e Itabira

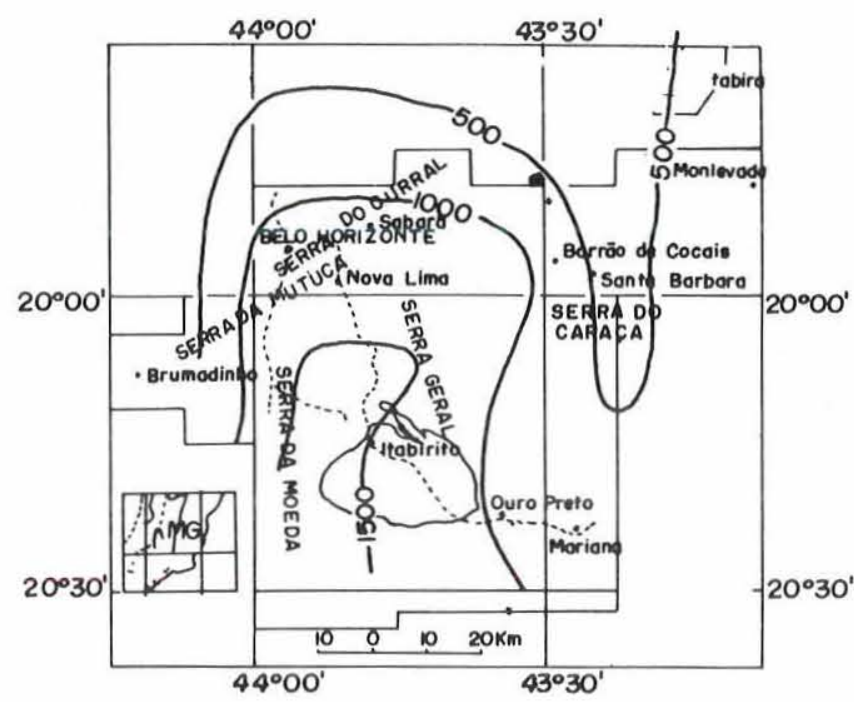

Figura 5 - Cartas isópacas dos grupos Caraça, Itabira e Formação Cercadinho

Gaivotas e de $150 \mathrm{~m}$ a oeste de Ibirité. Provavelmente sua espessura está entre 50 a $200 \mathrm{~m}$. A 6 km da Fazenda Alegrias é de $80 \mathrm{~m}$, sendo de $1.200 \mathrm{~m}$ na própria fazenda; Batatal - $30 \mathrm{~m}$; Moeda - a espessura máxima é de $300 \mathrm{~m}$ a este das Alegrias, indo para $200 \mathrm{~m}$ a oeste, sendo de 0 a $200 \mathrm{~m}$ na parte central.

Gongo-Sôco/Antônio dos Santos/Conceição do Rio Acima Moore (1969) foi quem cartografou esta região do Quadrilátero Ferrífero e, segundo este autor, as espessuras diversas formações quadrícula de Conceição do Rio Acima estão a mais ou menos $900 \mathrm{~m}$ ao norte da quadrícula de Gongo-Sôco/Antônio dos Santos. Nessa região também não aparecem as partes superiores do Grupo Piracicaba, sendo então somente constatada a presença da Formação Cercadinho; a Formação Sabará diretamente sobre a Cercadinho.

Cercadinho varia de $400 \mathrm{~m}$ a oeste de Conceição do Rio Acima para $150 \mathrm{~m}$ perto de Lagoa das Antas e Lagoa do Couto. É de $350 \mathrm{~m}$ próximo a Gongo-Sôco e de $200 \mathrm{~m}$ a nordeste de Gongo-Sôco; Gandarela - varia de 30 a $70 \mathrm{~m}$ a nordeste de Santa Bárbara e de 70 a $1.000 \mathrm{~m}$ na região de Gongo-Sôco e Conceição do Rio Acima. Passa a $750 \mathrm{~m}$ a nordeste de Gongo-Sôco, na região de Lagoa Grande mas já é de $100 \mathrm{~m}$ a nordeste desta região e a oeste de Gongo-Sôco. Ao norte, sua espessura varia entre 700 a 800 metros; Caue — varia de $400 \mathrm{~m}$ a oeste de Gongo-Sôco para $300 \mathrm{~m}$ perto da mina de Gongo-Sôco, e varia entre $100 \mathrm{~m}$ a $400 \mathrm{~m}$ na própria região de Gongo-Sôco. Varia de 100 a 650 m entre Gongo-Sôco e Conceição do Rio Acima. É de $650 \mathrm{~m}$ na região de Pico e passa a $300 \mathrm{~m}$ ao nordeste da região; Batatal - é de aproximadamente $300 \mathrm{~m}$ a oeste de Gongo-Sôco, passando a mais de $200 \mathrm{~m}$ a sudoeste da quadrícula de Conceição do Rio Acima; Moeda - é de 20 a 30 m na mina de Gongo-Sôco a mais de $200 \mathrm{~m}$ a sudoeste do sinclinal de Gandarela. Varia de 10 a $100 \mathrm{~m}$ a noroeste de Gongo-Sôco. 
Itabira a região de Itabira foi cartografada por $\mathrm{J}$. Door II a A.L. Barbosa (1963). Esses autores constataram a ausência das partes superiores do Grupo Piracicaba também ai nesta região. A máxima espessura cartografada do Piracicaba foi de 200 a 300 m, ao norte da cidade de Itabira.

Zona Oeste da Serra do Curral segundo Simmons (1968), que foi quem cartografou esta região, nós temos a seguinte disposição, abaixo. Esse autor também notou que a Formação Batatal é mais ou menos constante (em torno de $30 \mathrm{~m}$ ) em toda a região cartografada, e que a Formação Moeda varia apenas de $30 \mathrm{~m}$ perto da região de Brumadinho a oeste da serra, para mais ou menos 70 $\mathrm{m}$ na região este da quadrícula.

Sabará - 400 m; Barreiro - 0-40 m; Taboões - 30-100 $\mathrm{m} ;$ F. Funil - 100-410 m; Cercadinho - 80-120 m; Gandarela - 0-170 m; Cauê - 60-180 m; Batatal - 30 $\mathrm{m} ;$ Moeda $-30-70 \mathrm{~m}$.

Monlevade segundo Reeves (1966), na região que compreende a quadrícula de Monlevade, o Grupo Piracicaba é aí representado pelo Grupo Elefante, que é dividido em dois subgrupos; o basal chamado Pontame e que corresponde às formações Cercadinho, o Fecho do Funil e Taboões, e ao topo temos o gnaisse Bica, cuja espessura é desconhecida, e que pode ser correlacionado às formações Barreiro e Sabará. Nessa região, a série Minas tem mais de $870 \mathrm{~m}$ de espessura, segundo Reeves acima citado.

$$
\text { Elefantes } \mid \begin{array}{l|l}
\text { Gnaisse/Bica - não conhecido } & \begin{array}{l}
\text { Sabará } \\
\text { Barreiro }
\end{array} \\
\text { Pantame }-10 \text { a } 200 \mathrm{~m} & \begin{array}{l}
\text { Taboões } \\
\text { F. Funil } \\
\text { Cercadinho }
\end{array}
\end{array}
$$

Gandarela - 0; Cauê - 125-350 m; Batatal - 20-50 m; Moeda - 90-50 m; Barão de Cocais - Segundo Simmons (1968), na região de Barão de Cocais a série Minas é representada até a Formação Cercadinho, constituindo ai uma coluna de $400 \mathrm{~m}$ em média.

Cercadinho - $225 \mathrm{~m}$; Gandarela - $65 \mathrm{~m}$; Cамê - 64 $\mathrm{m} ;$ Batatal $-9 \mathrm{~m} ;$ Moeda $-9 \mathrm{~m}$.

Alegrias - Maxwell (1960) foi quem cartografou esta região no convênio USGS/DNPM, e é interessante notar que a Formação Taboões ai não foi cartografada. Hiato? Nessa região estão presentes os termos superiores do Grupo Piracicaba, indo até a Formação Barreiro.

Barreiro - 170 m; F. Funil - 175 m; Cercadinho - é de $80 \mathrm{~m}$ a 4 km de seç̧ão tipo; na Fazenda Alegrias é de $225 \mathrm{~m}$. Em Bento Rodrigues é de $210 \mathrm{~m}$; Itabira - Piracicaba - entre 200 a $300 \mathrm{~m}$ ao norte de Itabira; Gandarela - não tem uma espessura que permita sua cartografia; Cauê - a espessura verdadeira é entre 150 a 200 $\mathrm{m}$, sendo a espessura máxima de $500 \mathrm{~m}$ no pico da Conceição e a mínima de $10 \mathrm{~m}$ ao sul da cidade de Itabira;
Caraça - é maior que $150 \mathrm{~m}$ no pico da Conceição, sendo de $100 \mathrm{~m}$ no sinclinal Cauê. É maior do que $100 \mathrm{~m}$ a $45.729 \mathrm{~N} 44.722 \mathrm{E}$ e é de $750 \mathrm{~m}$ no anticlinal do Chacrinha e de $50 \mathrm{~m}$ em Dois Córregos.

Itabirito Wallace (1965) foi quem cartografou a região, ai achando as seguintes espessuras:

Barreiro - média de $120 \mathrm{~m}$; Taboões - de 40 a $2 \mathrm{~m} ; F$. Funil - de 100 a mais de 600 m; Cercadinho - de 400 a 900 m; Gandarela - é de 500 m na Lagoa do Miguelão, de $438 \mathrm{~m}$ ao sul de Água Limpa, de $361 \mathrm{~m}$ Canhão Estreito, e na Serra do Itabirito perto da Lagoa das Codornas é maior que $400 \mathrm{~m}$; Cauê - varia de $900 \mathrm{~m}$ ao norte do Canhão do Peixe a $100 \mathrm{~m}$ a sudoeste de Bação. Foi medida a espessura de $300 \mathrm{~m}$ e percebida a variação de $700 \mathrm{~m}$ a $200 \mathrm{~m}$. É de aproximadamente $300 \mathrm{~m}$ na Serra da Moeda; Batatal - é em média $100 \mathrm{~m}$ no distrito e de $200 \mathrm{~m}$ no Canhão Estreito a sudeste da Serra da Moeda; Moeda - na Serra de Itabirito chega a 900 m (Canhão do Rio Estreito) e menos de $200 \mathrm{~m}$ a sudeste do complexo. A média é de $550 \mathrm{~m}$.

CONCLUSÕES Algumas conclusões serão aqui feitas no intuito de auxiliar na visualização das grandes linhas geotectônicas da região leste e sudeste do Estado de Minas Gerais (e estados adjacentes a esta região mineira), no interesse principal de guiar futuros trabalhos ligados a interesses metalogenéticos nesta parte do território brasileiro.

1) Como conclusões antecipadas, isto é, conclusões já existentes antes da realização deste trabalho, tem-se:

1.1) A série Minas, na região do Quadrilátero Ferrifero, pertence ao miogeossinclinal, segundo Door II (1969).

1.2) Segundo mapas geológicos do Brasil de 1971, os grupos de rochas na região sudeste do Brasil que podem ser correlacionados em idade com a série Minas são: os grupos Andrelândia e o Grupo Araxá, ambos compreendidos entre 900 a 1.300 milhões de anos.

1.3) Segundo notas explicativas de Costa (1978), é principalmente no Grupo Araxá onde se encontra uma espessa série de grauvacas e rochas básicas-ultrabásicas. Estas rochas são de um contexto puramente eugeossinclinal quando conjuntamente associadas, e nesta associação não se encontra a presença de um vulcanismo alcalino relacionado às rochas ultrabásicas.

Segundo ainda textos explicativos da Carta Geológica do Brasil ao Milionésimo (Folha de Goiânia e Folha de Goiás, 1975), o Grupo Araxá é formado de metagrauvacas com intercalações de rochas verdes e possui um grau de metamorfismo que vai de mesozona (xistos a 2 micas) à catazona (gnaisses a 2 micas associados diretamente a rochas calcoalcalinas-granodioritos). Estes fatores afirmam uma vez mais o contexto eugeossinclinal de tais rochas. Evidentemente que se faz necessário um maior número de trabalhos geocronológicos das rochas vulcânicas (rochas vulcânicas intercaladas) aí encontradas, para que se possa fazer uma boa correlação com a seqüência de rochas do Grupo Rio daș Velhas. É interessante lembrar também aqui que o zoneamento meta- 
mórfico vertical é relacionado com os fácies geossinclinais (Dewey e Bird, 1970; Mattaeus, 1973), onde se tem:

No miogeossinclinal - metamorfismo à epizona, no máximo começo de mesozona.

No eugeossinclinal - metamorfismo de no mínimo mesozona; metamorfismo generalizado de meso à catazona .

1.4) Se no Grupo Araxá encontram-se a litologia e as características eugeossinclinais citadas, não se encontra o mesmo contexto no grupo de rochas denominado Andrelândia, onde constata-se, segundo Costa (1978), aí neste grupo de rochas, um vulcanismo intermediário a ácido, característica de um contexto vulcânico tardio a pós-orogênico, associado a molassas.

1.5) $\mathrm{O}$ grupo sotoposto ao Grupo Andrelândia, e possuindo características eugeossinclinais, é o Grupo
Barbacena, que é considerado pré-Minas por Costa (1978); aqui seria de se perguntar: estas dataçoes foram realizadas pelo método K-argônio? Se as dataçðes foram realizadas pelo método $\mathrm{K}$-argônio, pode ter havido um rejuvenescimento de tais rochas, e a datação indicará somente o último evento tectônico, devido a contaminações de intrusivas mais recentes.

1.6) Para a região a leste do Quadrilátero Ferrífero têm-se os grupos Paraíba e Juiz de Fora, também com fortes características eugeossinclinais e acordando com a carta de isópacas construída para a série Minas aí na região do quadrilátero (Costa, 1978).

1.7) Um fato interessante a se-considerar ao sul e a leste do quadrilátero é a seqüência de ocorrências de ultrabásicas (algumas com mineralizaçōes em níquel e cromo) que se alinham aí nesta região, subindo até a Bahia como proposto por Grossi (1968) (ver Fig. 6).

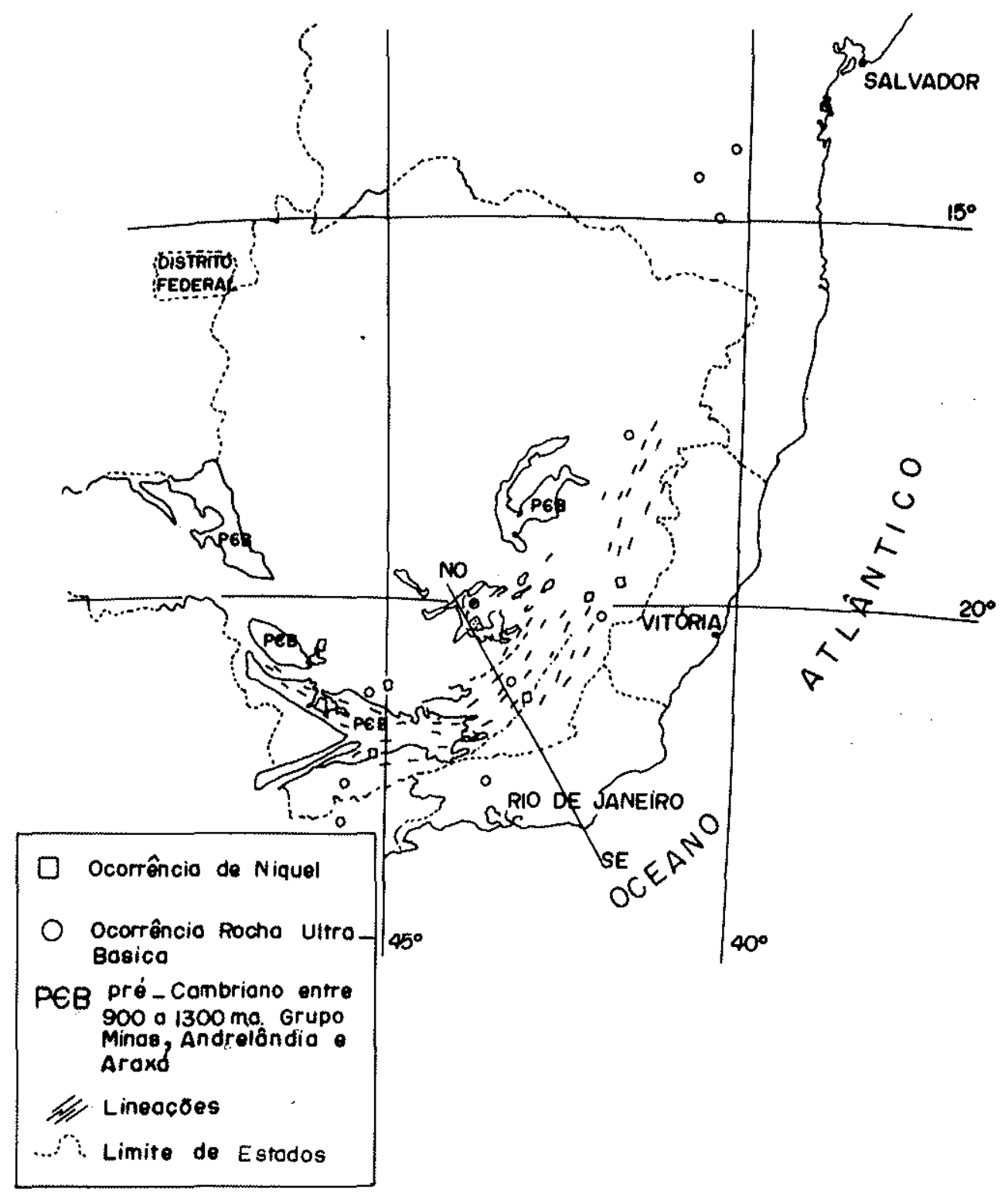

Figura 6 - Carta de distribuição das formaçðes precambrianas e de algumas ocorrências de ultrabásicas com Cr e Ni situadas entre 1.300 e $900 \mathrm{~m}$.a. na parte sudoeste do Estado de Minas Gerais. Os grupos Andrelândia, Araxá, Minas e lineaçðes dentro do Grupo Paraíba e do Grupo Juiz de Fora sâo também ai representados 
1.8) As inclinações dos planos axiais das dobras são indicadores dos sentidos dos esforços provocadores destes dobramentos (Mattaeus, 1973). Na série Minas, esses dobramentos e as grandes folhas de cavalgamento se desenvolveram, a grosso modo, de sudeste em direção ao noroeste (Door II, 1969).

2) Como conclusões do atual trabalho, têm-se:

2.1) O miogeossinclinal Minas, na região do Quadrilátero Ferrífero, teve um sentido de sedimentação, a grosso modo, noroeste em direção a sudeste, o que estaria completamente de acordo com a análise das inclinações dos planos axiais (conclusão 1.3), e que indicaria uma zona orogênica (eugeossinclinal) a sudeste-leste do quadrilátero (observar Fig. 4), e as regiões fontes de sedimentos estariam situadas a oeste-noroeste do Quadrilátero Ferrífero.

2.2) Dois fatos nos levam a pensar numa colisão do tipo continente-continente (ver perfil esquemático na Fig. 7).

2.2.1) A existência de uma zona a ultrabásica, sem associações a rochas ultrabásicas alcalinas, e que se situa entre um núcleo granulitico a características eugeossinclinais (Grupo Paraíba) e rochas de um contexto miogeossinclinal (série Minas) (Bird e Dewey, 1970).

2.2.2) Antes do Cretáceo, o continente brasileiro estava ligado ao continente africano, formando o grande continente Gondwana; logo, o geossinclinal Minas era intracratônico.

\section{IMPORTÂNCIA METALOGENÉTICA BASEADA NAS CONCLUSÕES ANTERIORES 1) As forma- ções ferríferas (Cauê e Gandarela) foram depositadas num miogeossinclinal, fato aliás já analisado por Door II e Barbosa (1963) e Door Il (1969). Conseqüentemente, as mesmas tiveram suas origens dissociadas dos vulca- nismos eugeossinclinais, associados a silexistos. São en- tão jazimentos associados às fácies de uma plataforma continental estável, depositados em lagunas; a origem desse ferro se deve então a erosões continentais de re- giôes de idade pré-Minas e que foram pré-enriquecidas em ferro possivelmente por efeitos climáticos. Estas re-}

giões devem estar situadas a oeste-noroeste da região do Quadrilátero Ferrífero.

2) Por haver existido uma plataforma precambriana, podem ser pesquisados jazimentos do tipo $\mathrm{Cu}, \mathrm{Pb}$, $\mathrm{Zn}, \mathrm{Mn}$, Au de plataforma, em fácies supratidais associados a estromatólitos ou antigos "reefs" (pequenos jazimentos). Mendelsohn F. pp. 645-662 em Walter (1976).

3) $\mathrm{Cu} / \mathrm{Co}, \mathrm{Pb}, \mathrm{Zn}, \mathrm{Au}, \mathrm{Ag}$ associados às rochas básicas, espilitizadas, agora dentro de um contexto de rochas gnáissicas. Antigas séries vulcano-sedimentares da época da formação do "eugeossinclinal-Minas". "Tipo Besshi"'.

4) $\mathrm{Cu} / \mathrm{Co}, \mathrm{Pb}, \mathrm{Zn}, \mathrm{Au}, \mathrm{Ag}$ associados a restos de antigos fundos oceânicos (contexto ofiolítico), mineralização ligada a rochas básicas espilitizadas deste contexto. "Tipo Cyprus".

5) Ni, Cr, Pt associados às rochas ultrabásicas, também restos de antigas crostas oceânicas, como no caso 4. "Tipo Cyprus".

6) Sulfetos associados ao vulcanismo intermediário a ácido na base das sequêencias molássicas (vulcanismo tarde orogênico-pórfiros, tufos de intermediários a ácidos etc.).

7) Sulfeto associado ao vulcanismo intermediário a ácido dentro de flyschs (exogeossinclinal). Tipo Huelva na Espanha ou Sullivan no Canadá.

8) Sulfetos nas molassas Andrelândia e série Itacolomi. Estas mineralizaçðes são conseqüências do item 6 . A erosão agindo sobre as rochas sotopostas (flyschs, vulcânicas do contexto orogênico tardio) incorpora parte destas mineralizações dentro das molassas. Tipo "redbeds".

Agradecimentos Quero aqui agradecer a colaboração das datilógrafas Rosângela Maria e Maria Ifigênia, do desenhista Zezinho, e sobretudo de Zélia, que datilografou com muito carinho a revisão final; finalmente quero aqui agradecer a todos que colaboraram com suas valiosas ajudas e permitiram assim a realização deste trabalho.

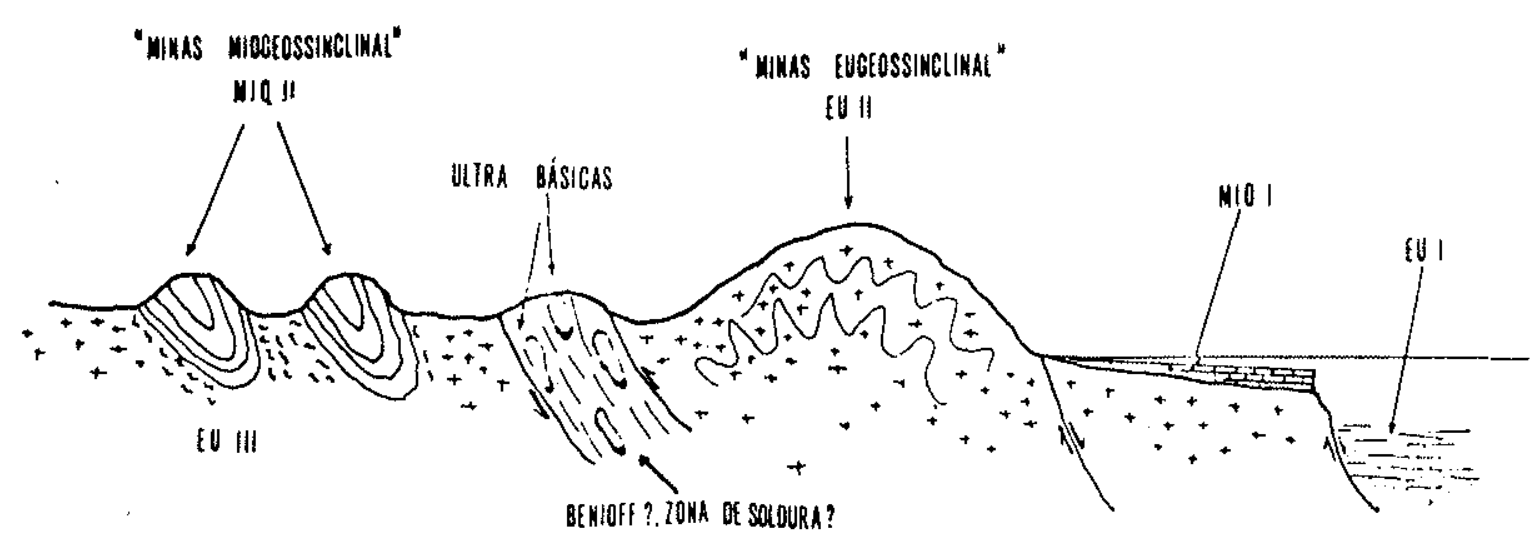

Figura 7 - Perfil esquemático do corte NO/SE da Fig. 6, que representa uma interpretação do autor, baseado em dados deste trabatho e na luz atual da interpretação de geossinclinais 


\section{BIBLIOGRAFIA}

ASQUITH, D.O. - 1970 - Depositional Topography and Major Marine Environments, Lade Cretaceens, Wyming AAPG - vol. 54/7, pp. 1148-1224.

AUBOIN, J. - 1965 - Geosynclines - Developments in Geotectonics Elsevier.

BERSIER - 1958 - Sequences Detritiques et Divagations Fluviales Eglogae Geol. Helv. 51, pp. $854-893$.

CLIFTON, H.E. HUNTEI, R.E. E PHILLIPS, R.L - 1971 - Depositional Structures and Process in the Non-Barred High Energy Nearshores. Journal Sed, Petrology - vol. $41, n$ ? 3 , pp. 651-670.

CONTESCU, L.T. - 1974 - Geologic History and Paleogeography of Eastern Carpathian. Example of Alpine Geosynclinal Evolution AAPG Bull, 58/12, pp. 2436-2476.

COSTA, M.T. - 1978 - Nota Explicativa - Mapa Geológico do Estado de Minas Gerais - Belo Horizonte.

DARDENṆE, M.A. e COSTA CAMPOS NETO, M. (1975) - Estromatólitos Colunares na Série Minas, MG, Revista Brasileira de Geociências -- vol. 5, n? 02.

DELFAUD, J. - 1974 - Typologie Scalaire des Séquences Sédimentaires en Fonction du miliéu de dépôt - B.S.G.F. (7) XVl, n? 06

DEWEY, J.F. E BIRD, J.M. - $1970-$ Montain Belt and the New Global Tectonics. Jour. Geophysical Research - vol. $75, n$. 14.

DIETZ, R.S. - 1963 - Collapsing Continental Rises - An Actualistic Concept of Geosynclines and Mountain Building. Journal of Geology - vol. n? 03, pp. 314-333.

DIETZ, S, - 1972 - Geosynclines, Mountains and Continent Building - Continents Adrift and Continents Adround - Scientific American, Freeman and Co., San Francisco.

DOOR II, J. VAN N. e BARBOSA, A.L.M. - 1963 - Geology and Ore Deposits of the Itabirite District, Minas Gerais, Brasil, USGS -. Prof. Paper 34 - C.

DOOR II, J. VAN N, - 1969 - Physiographic, Stratigraphic and Structural Development of the Quadrilatero Ferrifero, MG, USGS - Prof. Paper 641 A - Washington.

GROSSI SAD, I.H. - 1965 - VI Semana de Estudos (SICEG) - $1965-$ Complexos Uitrabásicos - Mineralizaçðes - Os Cinturỏes Serpentinicos do Brasil Oriental, pp. 140-153.

KAY, M. - 1951 - North American Geosynclines Geological Society of America - Memoir 48.

KRUMBEIN, W.C. e SLOSS, L.V. - 1963 -. Stratigraphy and Sedimentation, 2. ediçào, W.N. Freeman and Co., S. Francisco.
LOMBARD, A. - 1956 - Géologie Sédimentaire - Les Séries Marines - Pa ris, Masson éd.

LOMBARD, A. - 1972 - Séries Sédimentaires - Genése et evolution - Paris, Masson éd.

MATTAEUS, M. - 1973 - Les déformations des matériaux de l'écorce terrestre. Herman Paris - Collection Méthodes.

MATTEHEWS, R.K. - 1974 - Dynamic Stratigraphy - An introduction to Sedimentation and Stratigraphy. Prentice-Hall Inc., N. Jersey.

MAXWELL, C.H. - 1960 - Geology and ore deposits of the Alegria district, Minas Gerais, Brasil, USGS, Prof, Paper 341 - J.

MOORE, S.L. - 1969 - Geology and ore deposits of the Antonio dos Santos - Gongo-Sôco and Conceiçăo do Rio Acima quadrangles. Minas Gerais, Brasil, USGS, Prof. Paper 431 - I.

PETTIJOHAN, F.J. -1975 - Sedimentary rocks -2 a ediçăo. Edition Harper and Row Publishers - New York.

PETIIJOHN, F.J, POTTER e SIEVER - 1972 - Sand and Sandstone Springer - Verlag, Berlin, Hejdelberg, New York.

POMERENE, J.B. - $1964-$ Geology and ore deposits of the Belo Horizonte lbirite and Macacos Quadrangles. Minas Gerais, Brasil, USGS, Prof. Paper 34 I - D.

REEVES, R.G. - 1966 - Geology and mineral resources of the Monlevade and Rio Piracicaba Quadrangles. Minas Gerais, Brasil, USGS, Prof. Paper 341 -

SIMMONS, G.C. - 1968 - Geology and Mineral resources of the Bardo de Cocais - Area, Minas Gerais, Brasil, USGS, Prof. Paper $341-\mathrm{H}$.

SIMMONS, G.C. - 1968 - Geology and iron deposits of the Western Serra do Curral. Minas Gerais, Brasil, USGS, Prof, Paper 341 - G.

SIMMONS, G.C. e MAXWEL.L, C.H. - 1961 - Grupo Tamanduá da Série Rio das Velhas - Brasil - DNPM - Divisâo Geologia e Mineralogia - Bol. 211 .

VISCHER, G.S. - 1961 - Use of Vertical profile in environmental reconstruction - A.A.P.C. Vol, 49, n: 1; pp. 41-61

WALLACE, R.M. - 1965 - Geology and mineral resources of Pico de ltabirito district. Minas Gerais, Brasil, USGS, Prof. Paper 341 - F.

WALTER, M.R. - 1976 - Stromatolites - Developments in Sedimentology $-20-$ Elsevier.

WOOD, A. e SMITH, A.J. - 1969 - The Sedimentation and Sedimentary history of the Aberystwth geits. Geol. Soc. London. Quart. Jour. V. CXIV, II - pp. 163.195. 